\title{
Cortical Neural Response to Visual Navigation through a Virtual Environment
}

\author{
Zifan Wang ${ }^{1}$, Richard So ${ }^{1}$, Chehin Chan ${ }^{2}$, Arnold Wilkins ${ }^{3}$ \\ ${ }^{1}$ Computational Ergonomics Research Group, the Hong Kong University of Science and Technology \\ ${ }^{2}$ Cognitive neuroscience Group, the Hong Kong Polytechnic University \\ ${ }^{3}$ Centre for Brain Studies, University of Essex
}

\begin{abstract}
This poster reports the preliminary results of an on-going near infrared spectroscopy (NIRS) study conducted to examine cortical response to visual motion typically found in Virtual Reality (VR) applications. Comparing to watching a grey background, navigating through a virtual tunnel increased levels of oxygenated haemoglobin in visual cortex (around area V3). Potential benefits of the finding for reducing cybersickness are discussed.
\end{abstract}

KEYWORDS: Visual cortex, Near Infra-Red Spectroscopy, visual motion, cybersickness and oxygenated haemoglobin.

INDEX TERMS: simulation and behavior; psychology; immersion

\section{INTRODUCTION}

Near infrared spectroscopy (NIRS) can measure the changes of oxygenated and deoxygenated haemoglobin in localized cortical areas of human brain [24]. The main strength of NIRS measurement lies in its continuous fine temporal resolution $(100 \mathrm{~ms})$. This makes it ideal for studying functional changes in respond of treatment or stimuli that varies with time. In this study, NIRS response to optical flow stimuli when navigating through a virtual environment (VE) is examined. Such visual motion has been associated with symptoms of motion sickness $[2,6,9,20,21$, $25,26]$. The effect has been referred to as cybersickness or visually induced motion sickness (VIMS) [11, 12, 13, 18, 19, 22]. VIMS has been studied for many years but the neural mechanism is not fully known $[8,10,14,15,28]$. On average, $1 / 3$ of the population is affected $[6,23]$. A review of literature indicates that there is no study measuring NIRS responses associated with changes in symptoms of VIMS and / or vection sensation. Coutts and Wilkins (2008) reported significant increases in oxygenated haemoglobin and decreases in deoxygenated haemoglobin in the visual cortex of viewers watching a checkerboard pattern (similar to that shown in Figure 1) alternated with a grey background as compared to watching a grey background $[4,5]$. Although no NIRS studies have investigated vection, positron emission tomography (PET) studies have reported that watching roll axis circular vection-provoking stimuli will activate the medial parietal-occipital area and V6 as well as deactivate the deep posterior insular area [1].

\section{METHODS}

Eight participants were exposed to visual oscillation along the

Email of corresponding author: $\underline{\text { rhyso@ust.hk }}$ fore-and-aft axis of a virtual tunnel (Figure 1). The visual stimulus was presented on a binocular display system (Figure 2). Same images were shown to both eyes to avoid potential convergence and accommodation mismatch [27]. Viewers' heads were fixed to avoid effects of perceived response lags [16,17]. An oscillation frequency of $0.05 \mathrm{~Hz}$ was used because a previous study showed that viewing fore-and-aft visual motion at this frequency caused the highest level of vection (illusion of self-motion) [3]. Participants were exposed to a sequence of visual stimuli with 5, 7, 13 or 17 second duration in random order. Each exposure was separated by a resting period of $4,6,12$ or 16 seconds. This made up an 80 second data session and each participant exposed to 10 repeated sessions. During the resting period, a grey background was shown (Figure 3). The 32 channel Imagent function brain imaging system (ISS, Champaign, IL, USA) was used to measure the NIRS responses. Two transmitters and two receivers were placed near V3 area of the visual cortex areas on both hemispheres (about $35 \mathrm{~mm}$ vertically above the inion and about $30 \mathrm{~cm}$ from the mid-line symmetrically on each side).

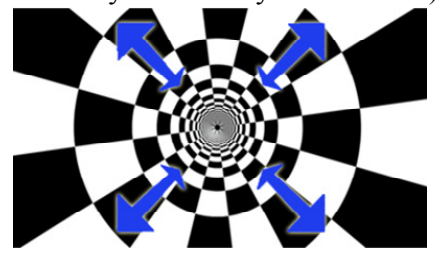

Figure 1. An illustration of the back and fore navigation motion through a virtual tunnel (the 4 blue arrows are not part of the stimulus, they illustrates the directions of expansion and contraction of the radial patterns).

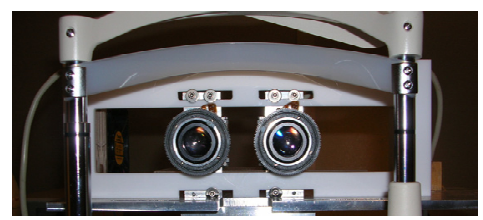

Figure 2. The binocular display system used to present the visual stimuli to the participants.

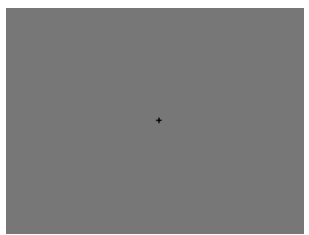

Figure 3. An illustration of baseline stimulus. 
The experiment is still on-going and the preliminary results of the first two participants indicated that the oxygenated haemoglobin levels increased shortly after the visual stimulus was shown and reduced shortly after the baseline grey background was shown (Figure 4). More data will be reported in the poster.

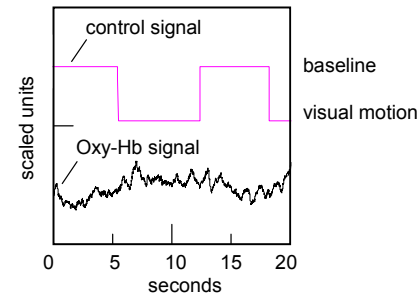

Figure 4. An illustration of the oxygenated haemoglobin signal verses the control signal.

\section{DISCUSSIONS}

This study demonstrated that navigating along fore-and-aft axis in a virtual tunnel can cause an increase in levels of oxygenated haemoglobin in the visual cortex area. The preliminary finding is important because it opens up the possibility to study how the brain responds to dynamic visual motion. Cybersickness has been agreed to be a major usability barrier of VR systems in ISO International Workshop Agreement 3 (IWA 3: [7]). Currently, both the Commission Internationale de L'eclairage (CIE) Technical Committee TC1-67 and ISO working group on dynamic image safety are developing guidelines for game industries [19]. If we could understand the neural mechanism of cybersickness, effective solutions to reduce visual stress associated with VR games can be developed.

\section{ACKNOWLEDGEMENT}

The authors would like to thank the Hong Kong Research Grants Council for partially funding this study through GRF HKUST619210.

\section{REFERENCES}

[1] Brandt, T., Bartenstein, P., Janek, A and Dieterich, M. (1998). Reciprocal inhibitory visual-vestibular interaction visual motion stimulation deactivates the parieto-insular vestibular cortex. Brain, 121, 1749-1758.

[2] Chen, R.W., Yuen, S.L. and So, R.H.Y. (2002) A progress report on the quest for a cybersickness dose value. Proc. of 46th Annual Meeting of the Human Factors and Ergonomics Society, Baltimore, MD, pp.2119-2123.

[3] Chow, E.H.C., Ji J.T.T., So R.H.Y. and Cheung, R.T.F. (2007) The effect of visual stimulus oscillation frequency on postural disturbance in roll and in fore-and-aft direction. Proc. VIMS2007, 10-12 Dec., Hong Kong. pp.165-170.

[4] Coutts, L., Cooper, C., Elwell, C. and Wilkins, A. (2010) Precision coloured filters reduce the hyperneuronal cortical response to visual stimuli in migraine. Awaiting publication.

[5] Coutts, L., Wilkins, A., Cooper, C. and Elwell, C. (2008) Visual stimuli for the assessment of treatment in disorders of light sensitivity using near infrared spectroscopy. Proc. Human Brain Mapping, Melbourne, Australia.

[6] Griffin, M.J. (1990). Handbook of Human Vibration. Academic Press.

[7] IWA3 (2005) International Workshop Agreement 3: Image Safety -- Protecting people against the health risks posed by visual image sequences. International Organization for Standardization, Geneva.
[8] Ji, J., So, R.H.Y., Lor, F., Cheung, T.F.R., Howarth, P. and Stanney, K. (2005) A search for possible neural pathways leading to visually induced motion sickness. VISION, 17(2):131-134.

[9] Ji, J.T.T., So, R.H.Y. and Cheung, R.T.F. (2009) Isolating the Effects of Vection and Optokinetic Nystagmus on Optokinetic Rotation-Induced Motion Sickness. Human factors, 51(5):739-751.

[10] Kennedy, R. S., Lane, N. E., Berbaum, K. S. and Lilienthal, M. J. (1993). Simulator sickness questionnaire: An enhanced method for quantifying simulator sickness. The international journal of aviation psychology, 3:203-220.

[11] Kiryu, T. and So, R.H.Y. (2008) Sensation of presence and cybersickness in applications of virtual reality for advanced rehabilitation. Journal of neuroengineering and rehabilitation, 4:34.

[12] Kiryu T., Uchiyama E., Jimbo M. and Iijima A. (2007) A timevarying factors model with different time-scales for studying cybersickness. HCI International, 22-27 July, Beijing, 262-269.

[13] Lo, W.T. and So, R.H.Y. (2001) Cybersickness in the presence of scene rotational movements along different axes. Applied ergonomics, 32(1):1-14.

[14] Money, K.E. and Wood, J.D. (1968) Neural mechanisms underlying the symptomatology of motion sickness. Fourth Symposium on the Role of the Vestibular Organs in Space Exploration, NASA SP-187.

[15] Reason, J.T. (1978). Motion sickness adaptation: A neural mismatch model. Journal of the Royal Society of Medicine, 71:819-829.

[16] So, R.H.Y. and Griffin, M.J. (1991) Effects of time delays on head tracking performance and the benefits of lag compensation by image deflection. Proceedings of Flight Simulation Technologies Conference, New Orleans, Louisiana, 12-14 August, pp.124-130.

[17] So, R.H.Y. and Griffin, M.J. (2000) Effects of target movement direction cue on head-tracking performance. Ergonomics, Vol.43, No.3, pp. 360-376.

[18] So, R.H.Y. and Lo, W.T. (1999) Cybersickness: An experimental study to isolate the effects of rotational scene oscillations. Proceedings of IEEE Virtual Reality '99 Conference, March 13-17, 1999, Houston, Texas. IEEE Computer Society, pp.237-241.

[19] So, R.H.Y. and Ujike, H. (2010) Visually induced motion sickness, visual stress and photosensitive epileptic seizures: What do they have in common? - Preface to the special issue. Applied Ergonomics, 41(4):491-493.

[20] So, R.H.Y., Ho, A.T.K. and Lo, W.T. (2001) A metric to quantify virtual scene movement for the study of cybersickness: Definition, implementation, and verification. Presence, 10:193-215.

[21] So, R.H.Y., Lo, W.T. and Ho, A.T.K., (2001) Effects of navigation speed on motion sickness caused by an immersive virtual environment. Human Factors, 43:452-461.

[22] So, R.H.Y. (1999) The search for a cybersickness dose value. Proceedings of the 8th International Conference on HumanComputer Interaction. August 22-27, 1999, Munich, Germany.

[23] So, R.H.Y., Finney, C.M. and Goonetilleke, R.S. (1999) Motion sickness susceptibility and occurrence in Hong Kong Chinese. Contemporary ergonomics 1999, Taylor \& Francis, pp.88-92.

[24] Villringer, J., Hock, P.C., Schleinkofer, L. and Dirnagl, U. (1993) Near infrared spectroscopy (NIRS): a new tool to study hemodynamic changes during activation of brain function in human adults. Neuroscience Letters, 154: 101-104.

[25] Webb, N.A. and Griffin, M.J. (2003) Eye movements, vection and motion sickness with foveal and peripheral vision. Aviation, space and environmental medicine, 74:622-625.

[26] Wilson, J. (1996). Effects of participating in virtual environments: A review of current knowledge. Safety science, 1:39-51.

[27] Wong, W.S., Yip, R., So, R.H.Y., Lam, A. and Ting, P. (2011) Benefits of matching the lens focus to the stereo depth in a binocular head-mounted display: A study on stereo fusion times. Presence.

[28] Young, L.R. and Oman, C.M. (1969). Model for vestibular adaptation to horizontal rotation. Aerospace medicine, 40:10761080 . 